\title{
Remaining Lifetime Assessment of Bucket Wheel Excavator's Boom Structure by Using Non-destructive Method
}

\author{
József ANDRÁS, ${ }^{1}$ József KOVÁCS, ${ }^{2}$ Endre ANDRÁS, ${ }^{3}$ Ildikó KERTÉSZ, ${ }^{4}$ \\ Ovidiu Bogdan TOMUȘ ${ }^{5}$ \\ University of Petroșani, Faculty of Mechanical and Electrical Engineering, Department of Mechanical, \\ Industrial and Transportation Engineering, Petroșani, Romania \\ 1 iosif.andras@gmail.com \\ ${ }^{2}$ kovacsi@mail.com \\ ${ }^{3}$ andrei.andras@gmail.com \\ ${ }^{4}$ kerteszildiko@ymail.com \\ ${ }^{5}$ tobogdan@gmail.com
}

\begin{abstract}
The bucket wheel excavators (BWE), when operating in faces with hard intrusions (rock structures with increased cutting resistance) are submitted to loads exceeding those arising during the operation in normal conditions. The most vulnerable structural element of the BWE from the point of view of these loads is the boom. The unexpected occurrence of hard formations produces shocks and vibrations, their unwanted effect being sudden failures of the constitutive elements and, in long term, fatigue, which increases the vulnerability of the mentioned structural element. In the paper we present the results obtained regarding the fatigue and remaining lifetime assessment using a new method, issued from the researches performed in the frame of BEWEXMIN project.
\end{abstract}

Keywords: bucket wheel excavator, fatigue, lifetime, surface hardness.

\section{Introduction}

Using surface hardness measurements on structural elements with a long history of cyclical loading as an indicator of the fatigue state, is relatively new in the analysis of structures.

The representative structures of this approach are mainly metallic bridges, cranes, load-carrying structures of buildings (mainly subjected to seismic loads), pipelines and other mechanical parts, such as gears.

In the past, the load carrying structures of huge earth-moving machines, such as bucket wheel excavators (BWE) became a subject of this approach [1].

It was determined that the fatigue resistance coefficient decrease can be correlated with Brinell Hardness (HB) increase in the case of steel.

Despite the different opinions of specialists regarding the so called cyclic softening-hardening of steels, the hardening process in the vicinity of zones suffering plastic strain has been confirmed. The remnant lifetime estimation of a crane's metallic structure using nondestructive methods is treated in [2]. The paper [3] deals with the remnant lifetime determination of mining equipment parts based on hardness increase. Underwater structures, such as steel pipes fatigue correlation with surface hardness change is presented in [4], while in [5] a hardness based method is presented for the lifetime evaluation of metallic bridges.

There are many published theoretical approaches, not all showing the direct correlation of hardening with the number of loading cycles. Such a correlation between the fatigue resistance coefficient (fatigue ratio) and Brinell Hardness has been statistically determined as in Figure 1. [6] The increase in hardness discussed in this paper, depending on the number of repetitive load cycles (determined on the basis of operating time), was found to have compared the increase in hardness 


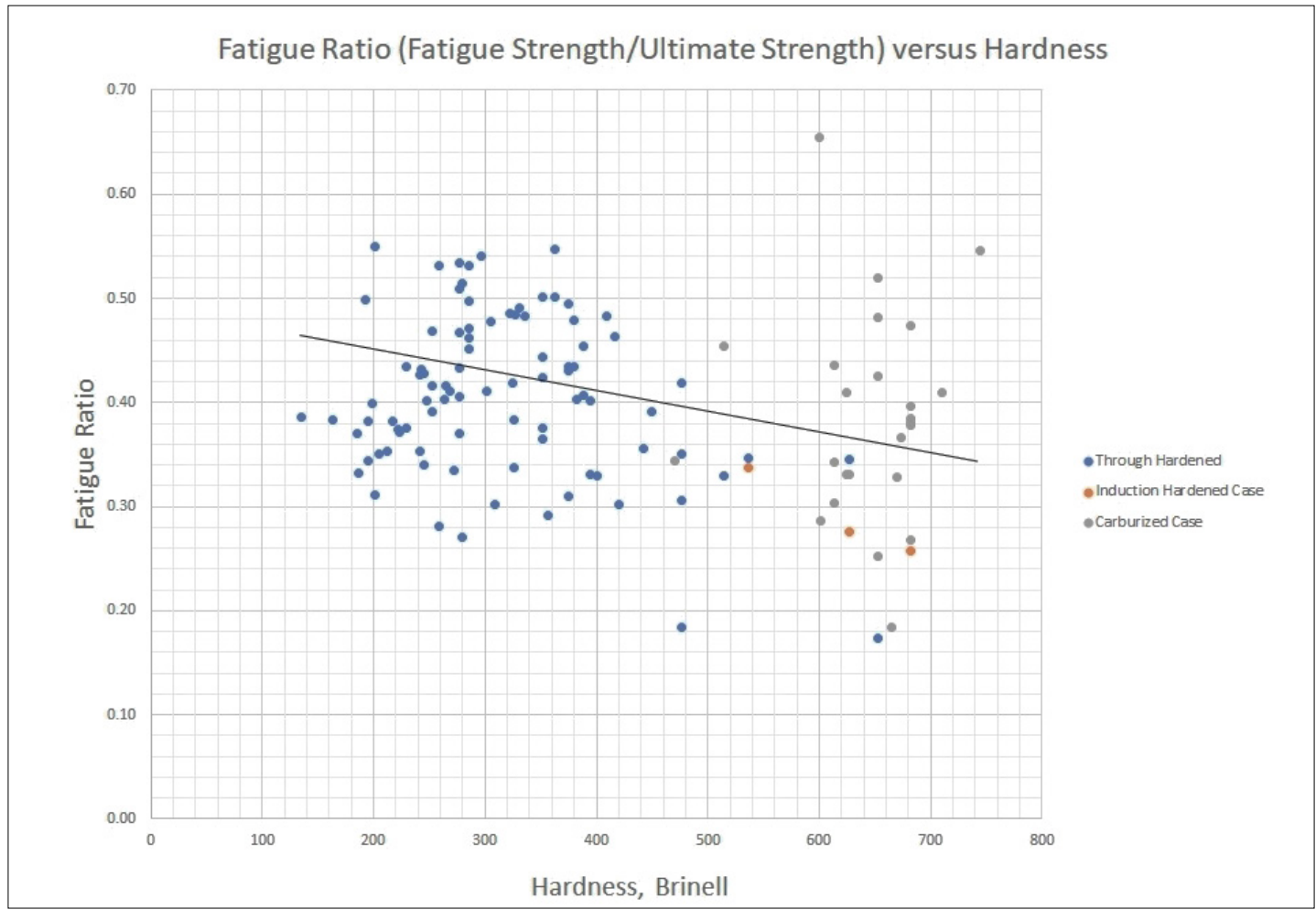

Figure 1. Brinell hardness increase with fatigue resistance coefficient decrease, according to [6].

measured on samples collected from the critical points of the excavator's boom structure, with original steel samples of the same brand, which were subjected to near the breaking tensile stress, The average Brinell Hardness variation of samples collected from BWE boom elements related to samples made from the same kind of steel, in the original state, has been plotted, according to Figure 2.

The hardness relative increase is significant, leading to the conclusion that the hardness can be

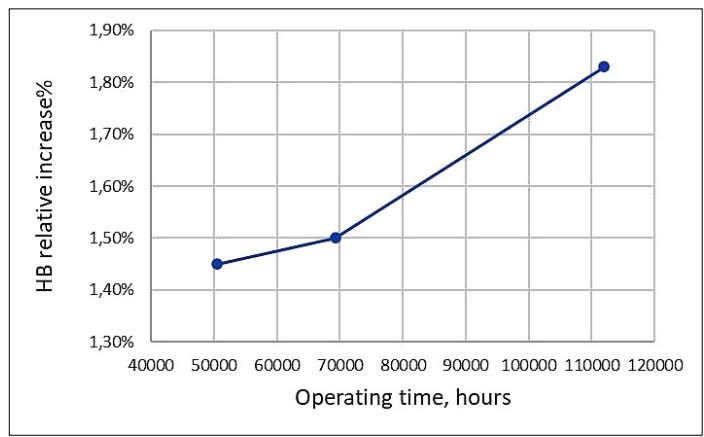

Figure 2. Brinell hardness relative increase as a function of operating hours. considered as an indicator of fatigue resistance, i.e. for the assessment of the remaining lifetime of the structure in case.

\section{Material and method}

In our approach, three types of measurements were considered, as follows:

- Joint hardness and tensile strength measurements on samples made by the same kind of steel as the BWE boom elements, revealing an increase of surface hardness increase in the proximity of breakage relative to the hardness in the body of the sample;

- Hardness and strength measurements on samples obtained from the BWE boom members, which where replaced during renewal of the respective structural element after failure;

- In situ hardness measurements on selected points of constituent elements of the boom, using a portable non-destructive Krautkramer MIC 20 hardness measurement device, the points being selected on the basis of FEM analyses and fault history of the given BWE.

We extended the hardness measurement on a batch of 7 machines - type ERc1400-30/7 - from 
different open pits from the Oltenia coal basin, on the same subassembly, and the bucketwheel boom.

In Figure 3 the average hardness has been plotted in correlation with the age of service of different BWE -s from which the samples were collected.

It can be observed that the general trend of $\mathrm{HB}$ is increasing, the last point value is due to the fact that the steel is of another kind than the rest of the BWE-s, other deviations are due to the averaging and different load history (less operating hours at same age).

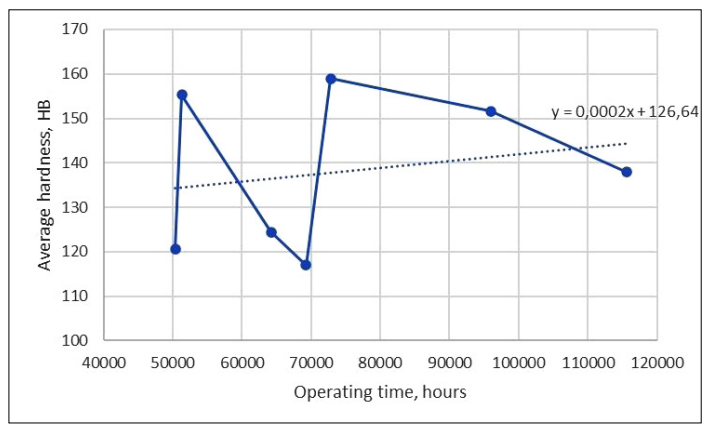

Figure 3. Evolution of average hardness according to operating time.
Nevertheless, the differences of hardness between different elements of the boom structure can provide useful information about the fatigue level of different structural parts, for the identification of those in which the probability of expected failures is greater.

We performed the hardness measurement on two machines type E 1400-307, 07 and 08, from the same open pit, under approximate temperature and excavation conditions to assess the hardness for which the structural properties of the materials are close.

From Figure 4 we can find that on average the decay of properties is not affected by the operating time between excavators, but there is a clear difference between left and right wall (girder).

Also, the graphs indicates a difference between the joints (nodes) which shows an asymmetry between left and right and a concentration of hardening at the extremities of the boom relative to middle segment.

This fact, along with correlation with other analyses can be useful for deriving a complex, multifactorial discrimination method for detecting the most vulnerable parts of the boom.

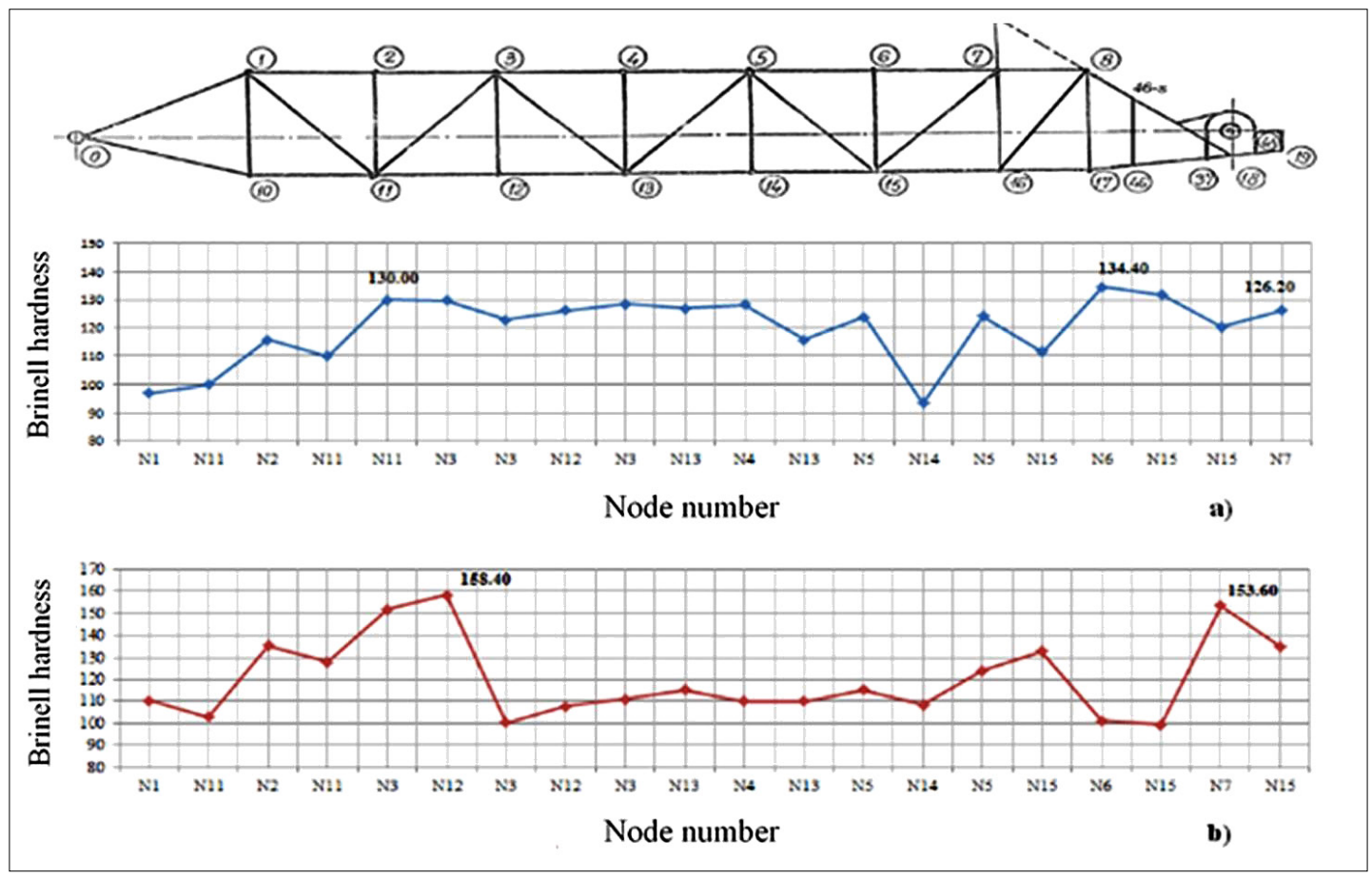

Figure 4. Distribution of the measured hardness on boom nodes. 


\section{Influence of the age of BWE on faults frequency}

The carrying structure of the BWE suffers in time degradation by fatigue that affects the functionality of these machines, degradations that can be generated mainly by decrease of fatigue resistance of materials.

The degradations that may occur over time on mobile heavy-duty machinery may be disposed of in the form of punctual charts of type defects for these machines. These charts have been drawn up after conducting the technical expertise of 25 machines used in lignite open pits

In Figures 5 and 6 different correlations between operating hours, failures occurred, throughput, rate of failure and production rate are presented.

By correlating the fault intensity with hardness growth, we can forecast the expected faults number dependence in terms of the average hardness, as in Figure 7.

\section{Conclusion}

Hardness based mechanical properties decay analysis is a useful method of investigating the change in structural features of mining machinery, and it can provide some information on the properties that evolve over time in the components of the load-carrying structure of the machine.

The hardness relative increase with the duration of service is significant, leading to the conclusion that the hardness can be considered as an indicator of fatigue resistance, i.e. for the assessment of remaining lifetime of the structure in case.

Different correlations between operating hours, failures occurred, throughput, rate of failure, production rate were derived, which are useful for state monitoring of the BWE carrying structure.

By correlating the fault intensity with hardness growth, it is possible to forecast the expected faults number dependence on the average hardness.

The differences of hardness between different elements of the boom structure can provide useful information about the fatigue level of different structural parts, for the identification of those in which the probability of expected failures is greater, which is useful for deciding the sensor placement location for state monitoring.
The results, in correlation with other analyses can be useful for deriving a complex, multifactorial discrimination method of detecting the most vulnerable parts of the boom.

The method presented is a new way to assess the state of the BWE-s and to forecast the remaining lifetime reserve.

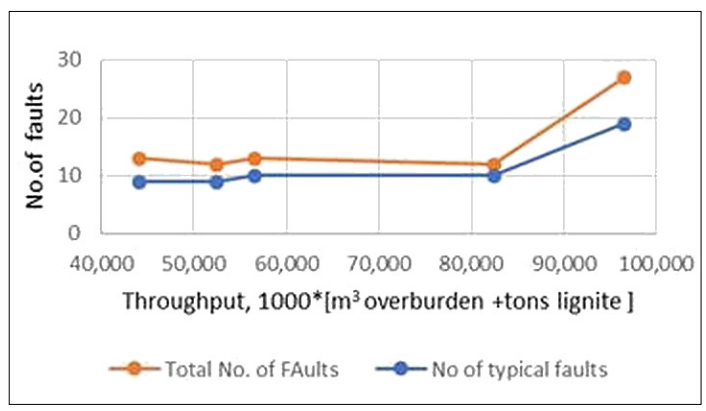

Figure 5. The number of failures according to the extracted lignite and overburden rock.

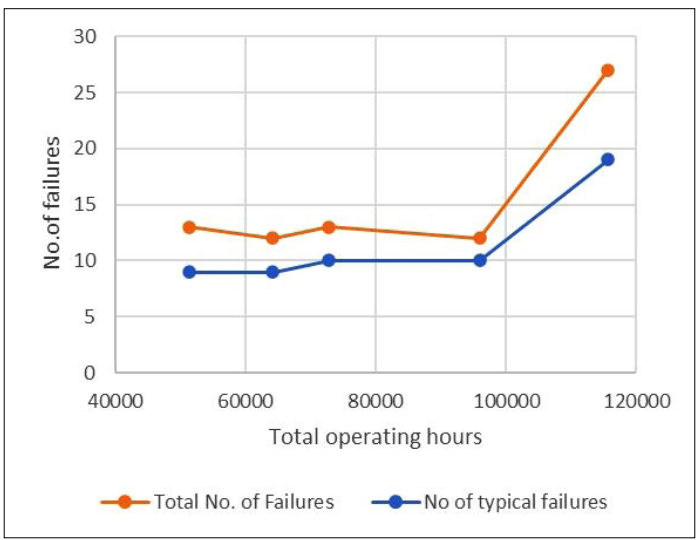

Figure 6. The number of failures according to operating hours.

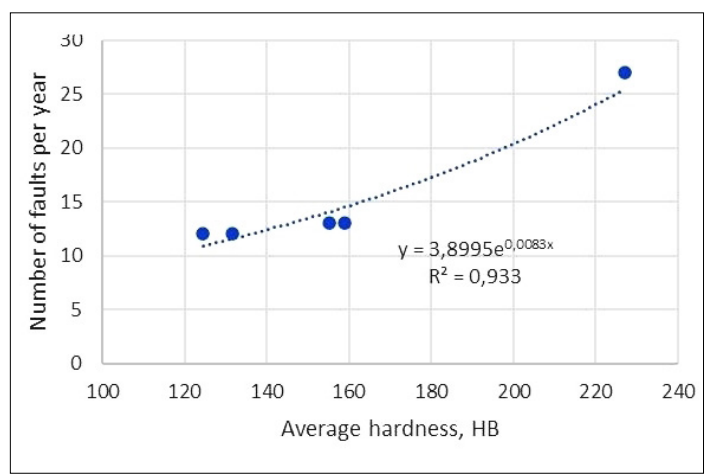

Figure 7. Correlation between fault intensity and hardness. 


\section{References}

[1] Boskovic S., Jovancic P., Ignjatovic D. et al.: Vibration as deciding parameter during revitalization process for replacing the bucket wheel drive. Journal of Vibroengineering 17/1. (2015) 24-32. https://www.jvejournals.com/article/15632

[2] Vîlceanu F., Radu S. M.: Methodology of establishing residual lifetime of lifting installation by non-destructive methods. $6^{\text {th }}$ International Multidisciplinary Scientific Symposium, Universitaria Simpro 2014, 10-11 october 2014, Petroşani.

[3] Zvonarev I. E., Ivanov S. L.: Analysis of changes in hardness of a metal surface layer in areas of high stress and methods of determining residual life of parts for mining machines. IOP Conf. Series: Materials Science and Engineering, 116 (2016) 012006

https://doi.org/10.1088/1757-899X/116/1/012006
[4] Drumonda G., Roudetb F. I.: High cycle fatigue damage evaluation of steel pipelines based on microhardness changes during cyclic loads. $23^{\text {ème }}$ Congrès Français de Mécanique Lille, 28 Août au $1^{\text {er }}$ Septembre 2017.

[5] Chaminda S. Bandara, Sudath C. Siriwardane, Udaya I. Dissanayake and Ranjith Dissanayake: Hardness-Based Non-destructive Method for Developing Location Specific S-N Curves for Fatigue Life Evaluation. Journal of Civil Engineering and Architecture 10. (2016) 183-191. https://doi.org/10.17265/1934-7359/2016.02.007

[6] Hardness versus Fatigue Strength, August 8, 2017 by Steel Market Development Institute https://barfatigueblog.org/2017/08/08/hardness-versus-fatigue-strength/ (accessed on: 15. 05. 2019.). 